\title{
Wanting to be wanted: a comparative study of incidence and severity in indirect complaint on the part of French and English language teaching assistants
}

\author{
ROBERT CRAWSHAW, JONATHAN CULPEPER \\ and JULIA HARRISON \\ Lancaster University
}

(Received August 2008; revised January 2009)

\begin{abstract}
A B S T RAC T
Using data from the ESRC funded project Pragmatics and Intercultural Communication (PIC), this paper applies contrastive quantitative and qualitative analysis to data derived from oral statements, logbooks and retrospective reports by language teaching assistants in France and England. The data concerns their 'rapport' (Spencer-Oatey, 2003; 2005) with the members of staff responsible for their professional supervision and the paper assesses complaint behaviour across the two national groups. Basing our study on computer recorded discourse segments taxonomically codified as 'negative assessment', we show that the incidence of 'indirect' complaint (Boxer, I993) is significantly higher among English assistants than among their French counterparts. A revised model for measuring 'severity' (House and Kasper, I98I; Olshtain and Weinbach, I993) is applied to the data using corpus linguistic techniques. Its findings demonstrate that English assistants also complain more 'severely' than their French peers. Nevertheless, the difference in linguistic behaviour between individuals within each group is shown to be greater than that between the two national groups, implying that personality is a stronger determinant of cultural outlook than nationality.
\end{abstract}

\section{INTRODUCTION}

Traditionally, 'complaint' was taught as a component of forensic rhetoric (Conley, I994). Until the advent of pragmatics, however, the topic was little studied as an object in its own right, other than from a purely descriptive or, more recently, structural/functional perspective (Halliday and Matthieson, 2004; Leech and Svartvik, I994; Martinet, I979). Since then, it has attracted closer attention from linguists, emerging most recently as a fertile ground for cross-cultural comparison: between speakers of different languages or genders (Olshtain and Weinbach, I987, I993) or in terms of its occurrence in different situations or discourse types (Boxer, I993; Köhl, 2006). Complaint has increasingly become seen as a signifier of cultural 
difference and one of the most complex features of negotiation, even between West European cultures which might be thought to share broadly similar traditions. As such, it is assumed to be governed by convention, both national and contextual, rather than by universal pragmatic principles (Spencer Oatey, 2003; 2005). Insofar as pragmatics was derived from the study of live interaction, it is perhaps not surprising that, notwithstanding recent interest in e-mail correspondence (Köhl, 2006), complaint should have been analysed primarily from a face to face perspective. Following Brown and Levinson (I978) and Leech (I983), Olshtain and Weinbach (I993: ro8) define complaint as

a speech act where the speaker (S) expresses displeasure or annoyance - censure - as a reaction to a past or on-going action, the consequences of which are perceived by $\mathrm{S}$ as affecting her unfavourably. This complaint is usually addressed to the hearer $(\mathrm{H})$ whom the $\mathrm{S}$ holds, at least partially, responsible for the offensive action.

By implication, this definition excludes what, following D'Amico-Reisner (I985), we refer to in this paper as 'indirect complaint', that is instances where the complainant is expressing his/her feelings to someone other than the person seen to be responsible for the source of the problem. Indirect complaint sheds light on 'how complaining functions as a social strategy' (Boxer, I993: I07). It serves as a window on the potential causes of cross-cultural misunderstanding and places them in a wider social, cultural and political context.

The corpus under review in this paper offers an example of the kind of indirect data just described. It emanates from an Anglo-French, ESRC-funded, project, Pragmatics and Intercultural Communication (PIC), aimed at identifying the factors cultural, linguistic, institutional, political, personal - which determine the outcomes of communication between language assistants and teachers in schools in France and England (see www.lancs.ac.uk/fass/projects/pic/ for details). 57 students (24 French and 33 English) from 8 universities and working in different types of school in England and France kept audio-recordings and written accounts of meetings with their mentors/responsables. The students participated in the project voluntarily. The results of a standard, globally recognised, academically approved, personality test showed them collectively to be well above average in all the 'Big 5 ' parameters: 'extraversion', 'agreeableness', 'conscientiousness', 'emotional stability' and 'openness' (http://www.lancs.ac.uk/fass/projects/pic/data/personalityresults). In their commentaries, they took advantage of the opportunity to express their reactions towards certain aspects of their professional experiences, both personally and in terms of what they saw as the wider cultural determinants of the behaviours they encountered. The conditions under which the students generated the data and their prior induction into the objectives and procedures of the project are described in detail in the project report (http://www.lancs. ac.uk/fass/projects/pic/outputs/reports). Following the principles of 'grounded theory' (Glaser and Strauss, I967; Richards and Richards, I99I), the corpus was word-processed and codified using the software programme Atlas ti5, reliability being qualitatively assured through regular meetings between codifiers before and 
during the process before being finally checked by the research assistant to the Project. It was classified according to a taxonomy of topics and 'speech types' (http://www.lancs.ac.uk/fass/projects/plc/data).

The data sample on which this paper focuses consists of segments of discourse codified as 'negative assessment', which we identified as co-terminal with indirect complaint in the terms defined above. For the purposes of this paper, these are defined as 'negative evaluation segments' (henceforth NES). Systematic qualitative and quantitative comparison between the two subsets just described revealed linguistic differences which we wish to argue are culturally marked. Using an approach derived from corpus linguistics and discourse analysis, our aim is to identify and define those differences, focusing on the incidence of complaint amongst the two sample groups and its degree of 'severity' (Olshtain and Weinbach, I993).

\section{TOPIC, CONTEXT AND BACKGROUND}

While topic is clearly an integral feature of complaint and is the most immediately tangible basis for cultural comparison, the principal focus of this paper is on language rather than on the cultural determinants of linguistic behaviour. We have explored elsewhere the main sources of concern expressed by the participants in the project, as well as their potential cultural and political implications (Crawshaw, 2005; Crawshaw and Harrison, 2007; Culpeper, Crawshaw and Harrison, 2008). At the same time, any comparison between the behaviour of the two experimental groups is only significant insofar as the underlying contexts in which they found themselves can be described as culturally equivalent. With this in mind, the following points concerning the design and outcomes of the study should be noted. Politically and institutionally, the national situations of the language teaching assistants corresponded to each other, whatever local contextual differences might have applied. It was inevitable that negative remarks were in some cases directed towards the person. However, the source of discomfort in the relationship might be due as much to the institutional environment as to behaviour on the part of the member of staff concerned. Unlike in England where the mentor was generally the head of the French department and could therefore control the assistant's timetable, in France, there was no equivalent position. The role of 'head of department' did not exist and the assistant was obliged to negotiate his/her timetable with a number of different teachers. It followed that more administrative initiative was demanded of the English in France than vice versa. The jobs they were required to undertake and the staff to whom they were responsible were more diverse. Many assistants were allocated to more than one school, thus doubling the amount of negotiation needed. It was not surprising therefore that English students complained more of 'disorganisation' and 'inefficiency', despite being aware that the limited role of the 'responsable' within the French system made the task of establishing a coherent timetable intrinsically more difficult. Clearly, no objective comment is being made about the strengths or weaknesses of either of the two educational cultures. These perceptions were those of the students themselves and have strictly relative status. 
Table I. Incidence of Third Party Complaint

\begin{tabular}{|c|c|c|}
\hline & English in France & French in England \\
\hline Total number of Students in sample & 33 & 24 \\
\hline $\begin{array}{l}\text { Total number of students who registered } \\
\text { NESs }^{I}\end{array}$ & 27 & I6 \\
\hline $\begin{array}{l}\text { Proportion of students registering NESs } \\
\text { expressed as a percentage of the national } \\
\text { cohort }\end{array}$ & $8 \mathrm{I} .8 \%$ & $66.6 \%$ \\
\hline Average number of NESs per student overall & $5.2 \mathrm{I} 2$ & 3.375 \\
\hline $\begin{array}{l}\text { Average number of NESs per student who } \\
\text { registered complaints }\end{array}$ & 6.370 & 5.062 \\
\hline
\end{tabular}

Despite some complaints on the part of French assistants at the lack of preparation from their English mentors, the reason that the system was criticised was less because it gave too much latitude to the assistant than because the syllabus prescribed too closely what the assistant was expected to do. French assistants were frustrated at having to devote time to the mindless reiteration of situational dialogues without being able to explain to pupils the meaning of the structures they were trying to learn. They were also sensitive to the failure of English mentors to fulfil verbal undertakings which they interpreted as evidence of insincerity or even hypocrisy. However, given that it is not the purpose of this paper to make cultural inferences but rather to present empirical findings, the object of complaint is less relevant in itself than as a factor in gauging incidence and severity, as will be demonstrated below.

\section{INCIDENCE}

Whatever the degree of equivalence in the topics giving rise to complaint, quantitative analysis of the data confirmed the initial impression that the incidence of complaint was significantly higher amongst the English informants than it was for the French.

Table I reveals that of the 33 English students participating in the project, 27 or $8 \mathrm{I} .8 \%$ of the experimental cohort - supplied data which included codified segments of discourse classified as 'negative'.

This compares with an equivalent 66.6\% amongst the French cohort in England. When combined with differences in the average number of NESs per student, the immediate conclusion to be drawn is that more English felt aggrieved than did their French counterparts, though this finding might equally be due to the fact that the French were being more respectful towards their English hosts, given that the research was being conducted by English nationals. The difference in the incidence of complaint between the English and the French assistants was nevertheless so marked that we thought it advisable to check whether variable distribution in the volume of NESs amongst the individual subjects had distorted

I The acronym 'NES' stands for 'Negative Evaluation Segment', meaning those segments in the corpus which were codified under the heading 'Negative Evaluation' 
Table 2. Distribution of complaint (English in France)

Incidence of complaint - English

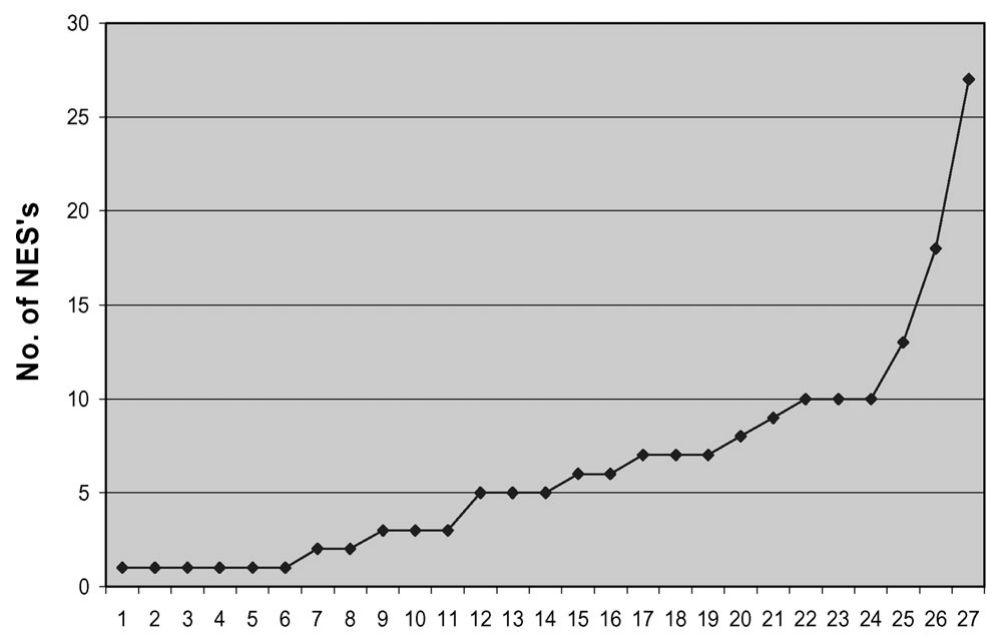

No. of Students

Table 3. Distribution of complaint (French in England)

\section{Incidence of Complaint - French}

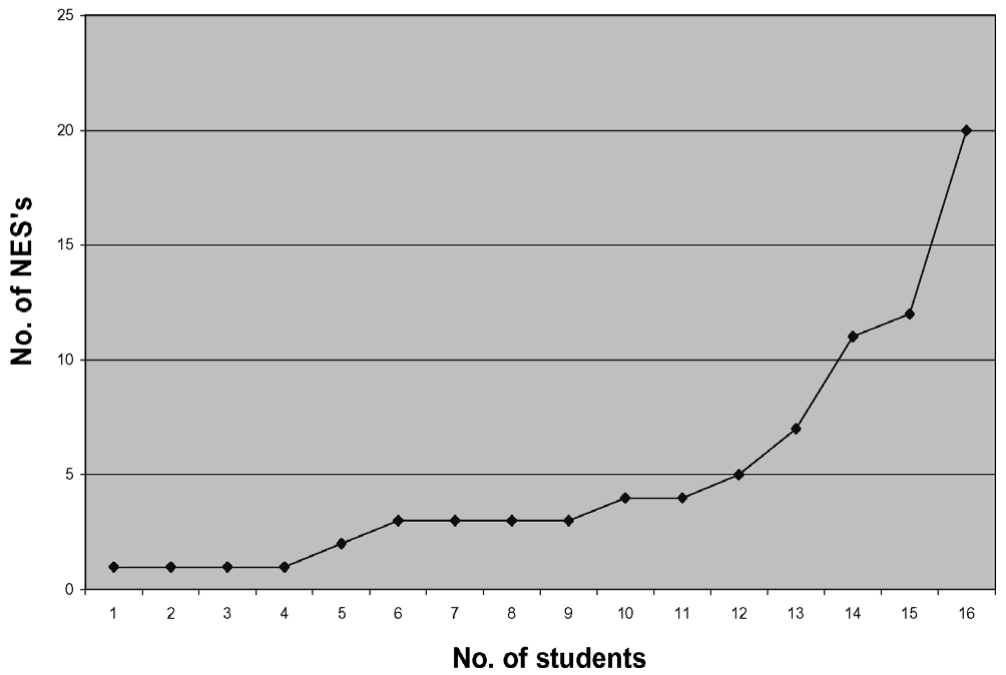

the figures. Tables 2 and 3 show that, on the contrary, the distribution curves of the two subject populations were very similar, corresponding in all likelihood to a similar differential in the range of personality and outlook within the two samples. 


\section{MEASURING 'SEVERITY'}

As distinct from most instances of complaint recorded in live situations, the indirect complaint data analysed in this paper was delivered in written or recorded form with no expectation that it would lead to action on the part of the recipient. This did not, however, preclude identifying the degree of illocutionary force conveyed by the language of complaint as a potentially relevant aspect of cross-cultural comparison. House and Kasper (I98I), Trosborg (I995) and Köhl (2006) have recourse to the terms 'intensifiers', 'upgraders' and 'downgraders' to identify specific features which serve to intensify or reduce the impact of the speech event. Together with other markers, these features, hitherto applied only to direct complaint, needed to be harnessed and simplified if degrees of severity in the data were to be captured and compared objectively.

We therefore reduced the collective components of the two most cited models in the literature on complaint: House and Kasper (I98I) and Olshtain and Weinbach (I993), to three fundamental parameters:

(I) Abstraction/concreteness: how clearly defined is the 'event' about which the complaint has been formulated?

(2) Objectivication/personalisation: (a) to what extent is an individual identified as being personally responsible for the event which has given rise to the complaint? (b) Correspondingly, to what extent does the complainant identify personally with the point of view expressed?

(3) Detachment/intensity: how 'strongly' expressed is the articulation of the complaint? i.e. in terms of the language used, how powerful are the feelings of the complainant about the incident?

In each case, through close analysis of the corpus, we sought to identify a series of features which might contribute to the weight to be attached to each parameter. Consider the following two examples of complaint concerning lack of professionalism:

(a) 'On reflection, I think that both teachers behaved in very unprofessional ways. I know they don't get on and I also know that they both want to help me [...] but I don't think it's fair of them to "bad mouth" each other to me'

(b) J'ai été surtout déçue par le comportement de certains. Je me suis rendu compte que quelques-uns (heureusement pas tous) sont très imbus de leur personne'.

In extract (a), concreteness markers are first, the referentiality of the phrase 'both teachers', insofar as the adjective 'both' and the designation of the profession 'teachers' clearly indicate that the complainant has two specific individuals in mind, a fact which is reinforced by the anaphoric repetition of the personal pronoun 'they' and 'both' and second, the simple past morpheme '-ed', which denotes a particular event in which the two colleagues 'bad mouthed' each other, so making explicit the cause of the complainant's feelings. By contrast, in (b), 'le comportement' is unmarked when juxtaposed with 'behaved' while 'both teachers' is marked when compared 
with the French 'certains', where the referent is not specified. 'J'ai été déçue' and 'Je me suis rendu compte' in (b) are less specific in terms of their location in time than the simple past tense of (a). Similarly, despite the ironic tone, the general attitude evoked by 'imbus de leur personne' is unmarked by comparison with the specific occasion invoked by 'bad-mouthed each other'. Overall, on the linguistic evidence, example (a) is more specific/explicit than (b).

From the perspective of 'objectivication/personalisation', (a) is apparently at a higher point on the hypothetical scale than (b). The first person singular pronoun 'I' occurs four times in (a) as against two occurrences of 'je' in (b) and is accompanied by an object pronoun 'me' which is antithetical to the 'them' of the previous phrase. The point of view in (b) is more distanced, more evaluative, whereas (a) is directly concerned with the relationship between the assistant and the two teachers concerned. A slightly different picture emerges if the same examples are considered from the strict point of view of 'intensity'. This is marked in (b) by the adverb 'surtout' and the choice of word 'déçue'. The 'I think' in (a) matches the 'Je me suis rendu compte' in (b), and a 'downgrading' effect is conveyed by the qualification in (a) of 'I know... but...' which reduces the intensifying effect of the metonymical 'bad-mouth'.

Thus, close analysis bears out an instinctive reading of the two examples, namely that despite being less 'intense' from a strictly technical point of view, the second, English, statement, is overall more 'severe' as an example of complaint due to the greater specificity of the event referred to and the extent to which blame is ascribed to the other party. The question was how far a methodology based on close stylistic deconstruction of individual extracts could be extended to the data as a whole. First, for each parameter, a reliable system of measurement was required. Meaningful features would need to be identified and subjected to corpus analysis, before eliminating examples deemed irrelevant. The compensatory effects of downgraders on upgraders would have to be taken into account. As with the measurement of incidence, any imbalance between the overall aggregates would need to be qualified by comparing the average occurrences of given features: in relation to the number of complainants and to the number of NESs.

\section{Abstraction/concreteness}

For strictly analytical purposes, deixis denoting concreteness was defined in terms of a limited set of linguistic features. These included demonstrative adjectives (this, that, these/ce, cet, cette, ces), demonstrative pronouns (it, that, there/cela, $\zeta$ a, celui-ci etc.), definite articles (the/le, la, les), and adverbs and adverbial phrases (when, then, a bit later, after a few minutes.../à ce moment-là, quand, lorsque, aujourd'hui, au bout du compte... etc.). Running a Wordsmith concordance on French demonstrative adjectives $c e$, cet, cette, ces yielded a total frequency count of I 3 I which could be reduced to 5 I by discounting occurrences of the emphatic relative form 'ce qui/ce que'. This compared with a total of I27 occurrences of the adjective 'this' amongst the English (following adjustment to take account of 
the higher number of English students registering NES's). The same disproportion applied to the occurrences of the definite article 'the' when compared to the combined aggregation of occurrences amongst the French cohort of 'le', 'la', 'les': 395 for the French versus 495 (adjusted) for the English: more than 25\% higher. Similar differences emerged when comparing adverbs of time. The aggregation of 'quand', 'alors', 'au bout du compte', 'ensuite', 'puis' and 'enfin' yielded a total of 62 occurrences, as against an adjusted total of 94 of the approximate English equivalents: 'when', 'then', 'at which point' and 'finally' (still $34 \%$ higher). The statistics appear to bear out the assertion that, as well as complaining more, the English students do so with a higher degree of 'concreteness' than the French, a finding which is all the more striking when it is noted that the average number of words per NES is only slightly more for the English than for the French (I 24 vs. I I9). It also seems from the high frequency of the adverbs 'when' and 'then' that, when describing the object of their complaint, they do so in narrative mode, with reference to a specific event which is related in more chronological terms than was the case for the French students.

\section{Agency/Personalisation}

It was immediately apparent from a reading of a NES to what extent the blame attached to the person rather than to the event perse. Within the data as a whole there was little to distinguish between the two cohorts. In each group, there were only two students who referred exclusively to the phenomenon giving rise to the complaint without using the behaviour of a particular individual as the primary motive for doing so. It revealed the readiness with which even sensitive and highly educated young people were predisposed to identify people with their cultural contexts. In the majority of cases, the process was metonymical: the behaviour of the individual was seen as a function of the institutional/cultural context or in more extreme cases, as an expression of previously held stereotypes of the host culture:

(c) Je m'attendais à un peu plus de chaleur et de communication, mais non, pas ici! C'est vraiment l'image que je me fais des Anglais pour le moment, après deux mois. Gentils, polis, courtois, ça il n'y a pas de problème. Mais quand il est question d'échanger, de communiquer, d'aller plus loin dans la communication, là les choses se compliquent sérieusement...'

(d) 'A cynic may say that Mme. G.'s reaction was typically 'French' because she has acknowledged that there is a problem but didn't attempt to remedy it Who knows?'

However, while 'agency/personalisation' relates in part to the person who is the object of the complaint, it is equally reflected in the degree to which complainants themselves identify with the source of the grievance. From this perspective, the English were significantly more personal in the way they described their experience. The data recorded a total of only 3 I 7 occurrences of ' $j e$ ' or ' $j$ " amongst the French. This contrasted with an equivalent (adjusted) total of 786 occurrences of 'I' on the 
part of the English. By any standards, the difference was striking. Was it really a feature of French linguistic behaviour that student native speakers writing personal commentaries in the context of a research project routinely eschew the first person pronoun in favour of more impersonal forms of expression? The findings pointed strongly in this direction.

\section{Intensity}

It proved possible to assess intensity using a mixed qualitative and quantitative approach by counting the occurrences of linguistic features such as superlatives and adverbial intensifiers, together with rhetorical figures such as metaphor, anaphora, accumulation, exclamation, expletive, irony, rhetorical questions and quotation. The features were systematically aggregated on the basis of close reading. Such an approach is clearly more subjective than corpus based analysis, but no less revealing. As an illustration of the method employed, consider the extract below from one of the more outspoken of the French informants:

(e) 'Actually I wasn't entirely satisfied. I feel so annoyed to listen to this interview, Ellen annoys me but I think it's because the interview was given only on a transactional level. Elle ne s'est pas mise à ma place sur le plan émotionnel. C'est expédié. Simple échange d'informations. J'étais vraiment lost et totalement dans l'inconnu, très fatiguée à cause de l'immersion linguistique. Et Ellen n'a rien donné, n'a rien dit pour me rassurer 'en profondeur', elle n'a pas demandé vraiment comment je ressentais les choses. Elle ne veut pas s'investir émotionnellement - entretien intellectuel, sans sentiments, sympa, sociable mais pas de vraie émotion et intérêt sincère. Sur le coup, je n'ai pas pris conscience vraiment que j'étais frustrée par cet entretien. Même ce que j'ai dit dans mon témoignage, on sent que je suis frustrée, je ne suis pas vraiment satisfaite de mon entretien. Je dis "Elle jouait un rôle, elle n'était pas elle-même quoi ". Elle est fausse ce qui ne pose pas les bases pour une bonne relation sur le plan interpersonnel, affectif.'

Intensity markers are highlighted in bold in the extract cited. The author clearly feels strongly that the interview has not gone well. Individual elements include adverbs such as 'so' and 'très', adverbial intensifiers ('vraiment', 'totalement'), the pronoun ('rien') and lexical items which can only considered dismissive in the context ('annoys', 'simple', 'frustrée, 'fausse'). In addition, the rhetorical impact of structural features can also be taken into account. Hence, the repetition of the adverbs 'vraiment' and 'totalement' in syntactically equivalent positions, together with the anaphoric negative forms (ne... pas) add to the force of the complaint, as does the double ellipses in apposition ('entretien intellectuel, sans sentiments'). The attitude of the complainant as revealed in this NES is, at the very least, uncompromising.

As with the marking of scripts written by foreign language learners, a combined quantitative/qualitative approach of this kind demands judgement. Nevertheless, as with language scripts, subjectivity can be minimised by sharing the process with more than one evaluator, and, if applied rigorously, highlights significant trends. If 
Table 4. Intensity Levels

\begin{tabular}{lcc}
\hline \hline & English in France & French in England \\
\hline Average no. of intensifiers per complainant & $3 \mathrm{I} .55$ & $\mathrm{I} 3.52$ \\
Average no. of mitigators per complainant & 7.48 & 3.23 \\
Average no. of intensifiers per NES & $5 . \mathrm{I} 6$ & 2.80 \\
Average no. of mitigators per NES & $\mathrm{I} .22$ & 0.67 \\
\hline \hline
\end{tabular}

Table 5. Differential comparison of intensity levels at the higher and lower ends of the scale

\begin{tabular}{lll}
\hline \hline & English in France & French in England \\
\hline $\begin{array}{l}\text { Average moderated number of intensifiers } \\
\text { (upgraders-downgraders) of the 5 }\end{array}$ & 73.6 & 33 \\
$\begin{array}{l}\text { highest scoring informants in the sample } \\
\begin{array}{l}\text { Average moderated number of intensifiers } \\
\text { (upgraders-downgraders) of the 5 }\end{array}\end{array}$ & I.4 & $-\mathrm{I}$ \\
$\quad$ lowest scoring informants in the sample & & \\
\hline \hline
\end{tabular}

the features are aggregated for the sample as a whole, the same startling differences emerge in the levels of 'intensity' as they did in respect of 'incidence'.

Adjusted to take account of the difference in the size of the two groups, the volume of intensifiers for the English was 2.73 times greater than that of the French. Expressed in terms of the average number of intensifiers per complainant the ratio of intensifiers of English to French was 2.I3: I.

Alongside this evaluative approach to the measurement of intensity, it was also possible to apply a standard corpus approach. Once again, the findings were startling and confirmed the overall impression gained so far. The word 'vraiment' occurred 26 times in the French sample against an adjusted total amongst the English of 48. 'Très' did not occur once amongst the French while for the English, the adjusted figure for 'very' was 57 ! Even if the underlying strength of feeling on the part of both groups of students were deemed to be equivalent, the evidence suggests otherwise and indicates strongly that the English were more extreme in the intensity as well as in the volume of their complaints.

Moreover, as Table 5 indicates, the adjusted average of intensity markers for the 5 lowest scoring French informants was $-\mathrm{I} .0 \mathrm{O}$ against an equivalent figure of $+\mathrm{I} .4 \mathrm{O}$ amongst the English. This is explained by the fact that at the bottom end of the scale, French informants recorded more downgraders than upgraders in their texts and therefore registered a negative score. Not only were the French students less prone to complain than the English, but those who did were more mitigated in their expression than their English counterparts, revealing it seems a lesser degree of conviction that they were necessarily in the right.

However, regardless of the comparative differences in linguistic behaviour between the two groups, one qualitative finding was clear. Expressed quantitatively in terms of the total number of upgraders minus the total number of downgraders, 
the differential range in the intensity of complaint by individuals far outweighed that between the two national cultures. The English may have been 2.13 times more 'intense' than the French in expressing complaint, but the findings recorded in Table 5 demonstrate that the degree of difference between the total number of intensifiers for the 5 highest and 5 lowest informants in each cohort was much greater. Thus whatever general differences may have existed between French and English assistants and the contexts in which they worked, personality was a far greater factor than culture in determining the extent to which students complained and the intensity with which they did so.

\section{CONCLUSIONS}

We have sought to argue in this paper that the analysis of complaint as a feature of intercultural pragmatics can usefully be extended to include indirect complaint. Our aim has been to compare the linguistic responses of two national groups of informants to a set of culturally equivalent situations. Our analysis has revealed that identifiable differences in the incidence and severity of complaint emerge between the sample groups. The data as read showed that English informants complained considerably more than their French peers, did so with greater intensity and, at the bottom end of the scale at least, qualified the expression of complaint less. However, within each sample, individual personality was a far greater determinant of volumes and intensity of complaint than cultural difference.

While it would be invalid to draw wider conclusions from such a statistically limited sample, the sharp differences revealed by the data raise questions which deserve to be further addressed. As we have argued elsewhere (Crawshaw and Harrison, 2007), although motivated by similar concerns, complaints on the part of language teaching assistants in France and England arise in response to institutional practices which are culturally and politically specific in origin. This paper shows further that the volume, mode and intensity of expression are also significantly different. Given that this was the first experiment of its kind, our approach should be applied in different contexts to other groups of language assistants before making wider cultural generalisations. However, when considering the validity of these findings, it should be noted that the sample groups were self-selecting and formally identified as 'agreeable, 'conscientious' and 'open'. Were the same experiment to be conducted on a national scale, the cultural implications of the findings might well be more extreme.

Address for correspondence:

Robert Crawshaw

Department of European Languages and Cultures

Lancaster University

Lancashire, LA1 ${ }_{4} Y N$

UK

r.crawshaw@lancs.ac.uk 


\section{REFERENCES}

Boxer, D. (1993). Social distance and speech behavior: the case of indirect complaints. Journal of Pragmatics, I9: I03-I25.

Brown, P. and Levinson, S. (1978). Politeness: Some Universals in Language Usage. Cambridge: Cambridge University Press.

Conley, T. (1994). Rhetoric in the European Tradition. Chicago: University of Chicago Press.

Crawshaw, R. and Harrison, J. (2007). Politics and pragmatics in the cross-cultural management of 'rapport'. Language and Intercultural Communication, Vol. 7 (3) 217239.

Culpeper, J., Crawshaw, R. and Harrison, J. (2008). Activity types as a bridge for micro and macro (politeness) research: contexts of culture in interactions between student foreign language assistants and their supervisors in schools in France and England. Multilingua: 297-324.

D’Amico-Reisner, L. (1985). An Ethnographic Study of Disapproval Exchanges. Cit. Boxer (I993). Unpublished $\mathrm{PhD}$ dissertation, University of Pennsylvania.

Glaser, B. and Strauss, A. (1967). The Discovery of Grounded Theory: Strategies for Qualitative Research. Chicago: Aldine.

Halliday, M. and Matthieson, C. (2004). A Functional Grammar of English. Second edition, London: Arnold.

House, J. and Kasper, G. (I98I). Politeness markers in English and German. In: F. Coulmas (ed.), Conversational Routine. Explorations in Sstandardised Communication Situations and Pre-patterned Speech. The Hague: Mouton, pp. I57-I85.

Köhl, M. (2006). 'Rotten Service!!' or 'Nie wieder!!!!!! - Complaining in British and German electronic discourse. Unpublished paper delivered at 3 Ist International LAUD Symposium, Intercultural Pragmatics. Landau, March 2006.

Leech, G. (1983). Principles of Pragmatics. London: Longman.

Leech, G. and Svartvik, J. (1994). A Communicative Grammar of English. London: Longman.

Martinet, A. (1979). Grammaire fonctionnelle du français. Paris: Didier.

Olshtain, E. and Weinbach, L. (I987). Complaint: a study of speech-act behavior among native and non-native speakers of Hebrew. In: M. Bertucelli-Papi and J. Verschuren (eds), The Pragmatic Perspective: Selected Papers from the 1985 International Pragmatics Conference. Amsterdam: Benjamins, pp. I95-208.

Olshtain, E. and Weinbach, L. (1993). Interlanguage features of the speech act of complaining. In: G. Kasper and S. Blum-Kulka (eds), Interlanguage Pragmatics. Oxford: Oxford University Press, pp. I08-I22.

Richards, L. and Richards, T. (I99I). The transformation of qualitative research: computational paradigms and research processes. In: N. Fielding and R. Lee (eds), Using Computers in Qualitative Research. London: Sage, pp. 38-53.

Spencer-Oatey, H. (2005). (Im)Politeness, Face and Perceptions of Rapport: Unpackaging their Bases and Interrelationships. Journal of Politeness research: Language, Behaviour, Culture, Vol. I.I: 95-I I9.

Spencer-Oatey, H. (2003). Managing Rapport in intercultural business interactions: a comparison of two Chinese-British welcome meetings. Journal of Intercultural Studies, Vol. 24(I): 33-46. 
A comparative study of incidence and severity in indirect complaint in French and English

Trosborg, A. (1995). Interlanguage Pragmatics. Requests, Complaints and Apologies. Berlin: Mouton de Gruyter.

\section{E LE C T RON I C}

Crawshaw, R. (2005). Pragmatics and Intercultural Communication: interim report on the PIC project to the British Council and the ESRC http://www.lancs.ac.uk/fass/projects/ $\mathrm{pic/data/docs/Interim \_ Report}$

Pragmatics and Intercultural Communication: the website of the PIC Project: http:// www.lancs.ac.uk/fass/projects/pic/ 